\title{
The importance of MPIS on RK for further ITS implementation in Malaysia
}

\author{
Sentot Imam Wahjono ${ }^{1, *}$, Muhammad Yusuf Khatir Bachok ${ }^{1}$, Anna Marina ${ }^{2}$, Mochamad Mochklas ${ }^{2}$
}

1Department of Technopreneurship, Universiti Teknikal Malaysia, Melaka, Malaysia

${ }^{2}$ Department of Accounting, Universitas Muhammadiyah Surabaya, Surabaya, Indonesia

\section{ARTICLE INFO}

\section{Article history:}

Received 24 May 2017

Received in revised form

20 July 2017

Accepted 1 August 2017

\section{Keywords:}

Intelligent transportation system

Passenger satisfaction

Public transport

Multimedia

Passenger information system

\begin{abstract}
A B S T R A C T
The aim of this study is to review the passenger satisfaction on information provided using Intelligent Transportation System (ITS) components by RK service, as a Public Transport in Malaysia. The method used in this research is quantitative method by questionnaire survey to the 100 passengers of RK. The result had showed that there are positive and significant correlations between ITS components which are Bus LED Destination, Bus Next-Stop Sign, Audio Voice Announcement System, Multimedia Passenger Information System (MPIS) and also Bus Station Display System with the Passenger Satisfaction in partially and also in simultaneously. In conclusion, this research will assist RK to identify the performance of implementation of ITS components in the bus towards the passenger satisfaction and can be used as reference to other bus company that want to implement the same system that can manage management of passenger information system. These research findings recommend improvement on the passenger information system.
\end{abstract}

(C) 2017 The Authors. Published by IASE. This is an open access article under the CC BY-NC-ND license (http://creativecommons.org/licenses/by-nc-nd/4.0/).

\section{Introduction}

Many studies have found that suburban resident drive more and walk less than a resident in traditional neighborhoods (Cao et al., 2009; Handy et al., 2008). Even so, the suburban resident still needs public transportation that makes it easy and fun. Transportation and urban development have closed relation (Stradling et al., 2007).

In a developed urban area, good traffic circulation system service has a key role for the ordered flows of people and information with high efficiency. In a developing country like Malaysia, the migration of people from the rural areas to the urban areas has progressed differently. For example, a city like Kuala Lumpur, high population density is supported by a multimodal system of cars, motorcycles, buses and trains. A mode of transport is a technological solution that used a fundamentally different vehicle, infrastructure, and operations.

Passenger information is information provided to public transport users about the nature and state of a public transport service, though visual, voice or touchable media. A distinction can be drawn between a) Static or Planned information, which

\footnotetext{
* Corresponding Author.

Email Address: wahjono@utem.edu.my (S. I. Wahjono) https://doi.org/10.21833/ijaas.2017.09.007

2313-626X/C 2017 The Authors. Published by IASE.

This is an open access article under the CC BY-NC-ND license

(http://creativecommons.org/licenses/by-nc-nd/4.0/)
}

changes only slowly and is typically used for journey planning prior to departure, b) Real-time information, which changes continuously as a result of real-world events and is typically used during the course of a journey (Chowdhury and Sadek, 2003).

Static information is made available traditionally in printed form through route network maps, timetable booklets, name signs and/or pictograms at stations and stops, etc. This information is also available through dedicated national and local telephone services. In many areas, static information is now being made available electronically through websites or over mobile phone services, typically via SMS (Adenso-Diaz et al., 1999).

Information is increasingly provided in the audio form as well, both on vehicles and at stops. Public address systems, usually but not always automated, will typically give next service announcements at stations and next stop announcement onboard vehicles using ICT (Musa, 2014)

Real time information is an advance on this, which recognizes the fact that public transport services do not always operate exactly according to the published timetable. By providing real-time information to passengers, they are better able to conduct their journey confidently, including taking any necessary steps in the event of delays. This helps to encourage greater use of public transport, which for many countries is a political goal. Real time information is provided over specialist passenger information systems. The core function of the ITS is a 
collection, management, and provision of real-time transport information (Suh et al., 2011).

On the bus network in Paris, monochrome LCD displays have been used since 1996 to indicate the time needed for a bus on a bus route to arrive at a bus stop, after a two-year trial period on a few bus routes. In the public transit sector, Intelligent Transportation System (ITS) represent a range of technologies including, but not limited to computeraided dispatch/automatic vehicle location (CAD/AVL), traveler information, electronic fare payment, transit security systems, automated passenger counters (APC), vehicle fleet monitoring devices, signal priority, and digital and mapping software applications. For several years, the bus operator has implemented a number of newer technologies which are being utilized to support the bus system, including those which improve on-time performance and reliability (Schweiger, 2003).

Most transportation professionals agree that society cannot simply build its way out of urban traffic congestion problems. As one of the several alternatives to costly build solutions, ITS provides the technology to enable people to make smart travel choices, and continued deployment of ITS strategies is an important component of bus service long-range and short- range transit plans (Wahjono, 2010).

ITS have created opportunities to respond proactively to increasing demand for efficient operation of public transit services and to convey information in a more timely manner to our customers. This includes global positioning system (GPS) technology that provides real-time schedule information to riders, electronic fare payment for greater customer convenience and faster boarding times, and devices that integrate with traffic signal systems allowing transit vehicles priority over other vehicles (Ferris et al., 2010) and the other technology adoption to satisfy customer (Abu et al., 2015).

This research is intended to investigate the satisfaction of passenger bus Rapid Kuantan, public transportation launched by the Malaysian government in December 2012.

\section{Literature survey}

Chowdhury and Sadek (2003) explained that ITS refers to a variety of tools, such as traffic engineering concepts, software, hardware, and communications technologies, that can be applied in an integrated fashion to the transportation system to improve its efficiency and safety. There are several concepts that are central to the ITS discipline. The first concept is that there are items of information that if gathered and distributed in a timely way, can positively affect how the transportation system functions and its safety. The second concept is that information collected and used in ITS can be of benefit to one or all of the following: the driver of a vehicle, the entity for whom a driver may work, pedestrians, transit riders, other member of the public and the public sector officials responsible for management of the transportation system (McDonnell and Madar, 2011).

Based on the third, ITS can only be truly effective nationally when a unified framework for integrating the many components of an ITS systems, called a systems architecture, has been developed and put in place. As this is being written, much is being accomplished towards producing such systems architecture for use by public agencies and private organizations alike. According to James and McBride (2010), the fourth concept is that ITS development and deployment requires expertise in a number of areas, including electronics, civil engineering, human factors, information management, satellite technology, public and private sector policy deployment and management practice and finance. It is not expected that each practitioner will have professional knowledge on all of these areas and thus the assembly of a team is the usual approach to developing and implementing ITS system. But it is important that those with electronic and computer skills be aware of the concern of the civil and mechanical engineers who develop and build roads and vehicles for example and that all engineers be aware of and understand the human limitations that may be involved in a use of a particular technology.

\subsection{Public transit and ITS}

Estimated six million people per day use public transportation in U.S.A. However, more than threequarter of a million American workers commute to work daily, using single-occupancy vehicles. This amount of traffic on our roads and highways cause traffic congestion, environmental pollution and wasted time. For many years, we have sought to solve the problems of traffic congestion, inefficiency, danger, and pollution by building more and wider highways. This approach is no longer adequate. The pouring of additional asphalt and concrete added capacity but it cannot keep pace with the increase demands of our transportations system. In response, the U.S.A Congress passed the Intermodal Surface Transportation Efficiency Act of 1991 (ISTEA). ISTEA called for the creation of an economically efficient and environmentally sound transportation system that will move people and goods in an energyefficient manner and will provide the foundation for a competitive American transportation industry. That new paradigm was reinforced in 1998 with the enactment of the Transportation Equity Act for the 21st Century (TEA-21). A broad range of diverse technologies, known collectively as intelligent transportations systems (ITS) holds the answer many of America's transportation problems. ITS comprises an array of technologies into our transportation system will save lives, time and money (Shende et al., 2017).

\subsection{ITS components}

Bus riders constantly need to know the status of their bus whether in a station, at a bus stop, or riding 
an unfamiliar bus route. Bus systems provide riders with complete information no matter what stage of their trip. The range is from hardware to software, LED to LCD-TFT, from onboard to stationary, and from the bus stop to the last stop. According to Chorus et al. (2007) there are several ITS components that had to be implemented in the bus service and the components that compatible and relevance with the research regarding satisfaction of passenger on information provided by bus service are Bus LED Destination Sign, Bus Next-Stop Sign, Audio Voice Announcement System, Multimedia Passenger Information System and Bus Station Display System.

\subsubsection{Bus LED destination}

Bus LED Destination is a sign mounted on the front, side or rear of public transport vehicles, such as a bus, tram/streetcar or light rail vehicle that displays the vehicle's route number and destination, or the route's number and name on transit systems using route names. It uses light-emitting diode (LED) panels that can show animated text, colors and a potentially unlimited number of routes. The main such sign, mounted on the front of the vehicle, usually located above the windshield, is often called the head sign, most likely from the fact that these signs are located on the front, or head, end of the vehicle. Depending on the type of the sign, it might also display intermediate points on the current route, especially if the route is particularly long and its final terminus by itself is not very helpful in determining where the vehicle is going. The bus LED destination sign has an unparalleled visual impact. Through high definition characters, 120 horizontal visibility, and automatic brightness control, the electronic signs are easily visible day and night and in many weather conditions. They are built to be both lightweight and inexpensive to maintain due to the elimination of moving parts and the long life of LED. The bus LED destination sign is part of a comprehensive and modular passenger information system. The LED displays can be connected with an audio system and multimedia LCD-TFT monitor system can be used to show next stop and route progress information, service advisories, and both still and video advertising.

\subsubsection{Bus next-stop sign}

The bus next stop sign provides bus passengers with the location of the next stop on a LED display in one color or two colors of text. The next stop display can be installed with an audio voice announcement system to be able to serve both the visually and hearing handicapped. The next stop sign works independently of the bus driver through GPS, an electronic gyroscope, and an odometer in conjunction with a pre-programmed route map. Built-in analytics allow the system to function even when the GPS signal is lost (Westerheim et al., 2007).

\subsubsection{Audio voice announcement system}

Audio Voice Announcement System is an electronic sound amplification and distribution system with a microphone, amplifier, and loudspeakers used to allow a person to address a large public, for example for announcements of movements at large and noisy air and rail terminals.

The Audio Voice Announcement System enhances the electronic destination sign to announce the bus line and destination at the terminal and in the bus. At the terminal, the bus operator will be announcing the information regarding the bus route and bus platform by using the big and large speaker. This will help the passenger to get information through the human factor.

For in the bus operation, the Audio Voice Announcement System is independently controlled by the driver. It is integrated with the Multimedia Passenger Information System that shows the current location of the bus. The announcement will be made to inform some destination programmed by the bus operator. The messaging can be repeated many times to ensure everyone can understand.

\subsubsection{Multimedia passenger information system}

The onboard multimedia Passenger Information System displays multimedia content including text, images, animations, video, and audio on a highresolution LCD-TFT monitor. Content possibilities range from next stop announcements to service advisories to video advertisements. The Infotainment System keeps everyone on board informed about the next stop and the bus's position along the route, including the visually and hearing handicapped. The Infotainment System greatly enhances the transit agency's service perception. The LCD-TFT monitor can be configured for singlesided, double-sided, or side- by-side viewing. The multimedia Passenger Information System can be managed independent of the driver and connected to a central controller through Wi-Fi, GPRS, and similar wireless formats. The central controller is able to manage the content for each individual bus, line, or the entire system using the included Multimedia Manager.

Rapid Kuantan has installed Asia Media TVs to attract customers. There are two LCD screens at the front and middle of the bus. Mostly the show is about a short advertisement, cartoon, movie trailer, fun and laugh series, Mr. Bean and more.

\subsubsection{Bus station display system}

Bus Station Display System is an electronic information system which provides real-time passenger information. It may be used both physically within a transportation hub and remotely use a web browser or mobile device. The Bus Station Display System provides complete passenger information throughout a bus station-from entry to 
departure. The main display is the arrival and departure board, which shows the bus line number, origin/destination, arrival/departure time, platform number, and additional lines for service messages.

As passengers move into the waiting and ticketing area, both LED display and LCD-TFT monitor that provide summary arrival and departure information. And at the platform, they have LED displays that show the appropriate schedule information for that platform. For Rapid Kuantan, it has the LCD monitor at the terminal to provide the information regarding the bus schedule and platform

\subsection{Passenger satisfaction}

Passenger satisfaction is fundamental to the practice of consumer sovereignty. Recently, many researchers stress that customer satisfaction has become an important issue for marketing practitioners because of the rapid business environment. Passenger satisfaction can be defined as a judgment made on the basis of a specific service encounter. Satisfaction and loyalty are not surrogates for each other. According to Wen et al. (2005), it is possible for customers to be loyal without being highly satisfied and to be highly satisfied and yet not loyal. Firms are needed to gain a better understanding of the relationship between satisfaction and behavioral intention in the online environment and to allocate the online marketing efforts between satisfaction initiatives and behavioral intention program (Yao et al., 2014). Moreover, the results from this research would assist bus service managers to better serve their customers, monitor, and develop service quality to achieve the highest level of their passenger's satisfaction.

Aguilera (2008) explained that traveler information should be provided before or during a trip. The pre-trip information provides a way to plan path, the mode of travel, and identify stops along the way. Because travel conditions can change once a trip has started, the ability to access traveler information during the course of the journey (endroute information) will also be useful.

There are four principal considerations for the provision of passenger information, static or real time (Caulfield and O’Mahony, 2003):

1. Data availability. Information could provide where it is available, and collect information can be resource intensive. Also, there may be difficulties in one organization (say an operator) allowing other organizations to access its information.

2. Data accuracy. Collecting information is errorprone, particularly when it is passed between systems manually. Also, prediction algorithms are not perfect, and real-time announcements may be in error for this reason.

3. Getting information to the passenger. A variety of dissemination mechanisms may be used, but it is not always easy to ensure that the correct information reaches the passenger when it is most needed. Apart from the obvious economic considerations, information overload must be avoided.

4. Latency or Response time. Information provision must react quickly to a passenger request or a real-world update. There is little point in announcing a service three minutes after it has departed.

\subsection{Relationship between ITS with passenger satisfaction}

ITS give benefits to the passenger. Good, accurate and easy-to-use transit service information is one of the most important factors in a potential transit rider's decision on whether or not to use transit. Being well informed goes a long way toward instilling a high level of confidence and comfort in using the system and being assured that the trip will be relatively stress-free and will take place as planned (Szyliowicz et al., 2016).

The advent of real-time information takes service information to a much higher level, in that delays and reliability issues are taken into account and the information is (or at least should be) very accurate. As a result, the comfort and confidence level of passengers is greatly enhanced, and more people will use the service and will be more likely to use it on a regular basis. This has been the case in many systems where, through surveys, passengers have identified real-time information, especially the variable-message arrival displays at stations, as one of the highest factors in their decision to use the service.

The primary customer benefit of Multimedia Passenger Information or Transit TV has improved customer information. Station and vehicle displays can provide customer information and alerts, and even be a platform for displaying real-time transit information such as next stop announcements, the vehicle's location on a map, and so on. It can also provide real-time news and weather content, which may be of value to customers. In some cases, a significant share of passengers has been found to use Transit TV as their primary sources of daily news and weather. In these instances, Transit TV can provide increased enjoyment of transit and reduce the perceived travel times. It may also increase customer perception of a premium level of service, and thus appeal to new transit market segments (Caulfield and O'Mahony, 2003).

Transit TV can also provide a way of focusing advertising in one location, and eliminate other forms of ads, which can reduce visual clutter. If it is a platform for dynamic and targeted ads, customers may find it preferable to traditional static billboards. However, Transit TV also carries a substantial risk of visual clutter that competes with branding, wayfinding and customer information. In addition, it is seen as highly intrusive by some passengers and could substantially degrade their perception of the transit service (Solomon et al., 2008). 
The ITS components bring major impact to the passenger satisfaction. From the perspective of passenger information, ITS components help passenger and bus operator to exchange information regarding the traveling. But because of a different kind of people values the technology differently, the level of satisfaction towards the ITS components may be different to one another. Thus the most relevance and non-relevance ITS components need to be identified as improvement in providing information to the passenger. In overall, the ITS components is really given benefits to the bus passenger and satisfaction of the passenger is gain from the good use of the advanced technology (Alexander and Hill, 2006).

\section{Methodology}

This research uses a quantitative approach through surveys. Questionnaires are distributed to all passengers in Rapid Kuantan bus services. The questionnaire is developed based on issues raised by past researchers and studies, as well as concerns mentioned in the literature related to ITS dimensions. In order to see if the result of this research is consistent with past literature, the researcher tried to match specific items with satisfaction issues. Items are measured using 4 point-Likert-scales ranging from strongly disagree to strongly agree. The respondents took approximately 15 minutes to complete the questionnaire. Respondents were assured that their individual responses would be kept confidential. The researchers use Statistical Package for the Social Sciences (SPSS) 19.0 to analyze the data.

The validity of this instrument was assessed through content validity, pre-testing, and revision of questionnaire. The researchers then conduct reliability test for each construct to assess the goodness and reliability of the measures.

This research consists of 5 independent variables (X): 1) Bus LED Destination, 2) Next-stop Bus Sign, 3) Audio Voice Announcement System, 4) Multimedia Passenger Information System, 5) Bus Station Display System and one Dependent variable $(\mathrm{Y})$ is Passenger Satisfaction. The instrument of this research is questionnaire as many as 5 questions $\mathrm{X} 1$, 5 questions $\mathrm{X} 2,4$ questions $\mathrm{X} 3,4$ questions $\mathrm{X} 4,5$ questions $X 5$, and 4 questions $Y$.

From validity test results there are 3 items of invalid questions are Q1.1, Q2.2, and Q5.2. Then the invalid item will be dropped, so there are only 23 questions circulated to the respondents. The survey usually takes minimum 5 minutes depending on the passenger's availability and readiness to answer it. Some passenger avoids from answering the survey due to not feels comfortable on doing anything when the bus moving.

Overall, there are 100 respondents that had completed answered the survey and the data regarding the route and number of respondent are shown in Table 1 . The most of the respondents were gain from route to Gambang because the destination is quite far and the number of passengers is quite large. But it still just $50 \%$ of the total respondent that should be received from the route which 50 from the route. The highest percentage rate that the researcher had was Teluk Cempedak route which is $75 \%$ of the respondent that should be received at the route. So, the researcher should ask for help from other people as enumerators to achieve the target sample which is 375 respondents.

Table 1: Questionnaire distribution

\begin{tabular}{cccc}
\hline $\begin{array}{c}\text { Bus Route from } \\
\text { Kuantan to }\end{array}$ & Sample & $\begin{array}{c}\text { Answered } \\
\text { Completed }\end{array}$ & $\begin{array}{c}\text { Response } \\
\text { rate }\end{array}$ \\
\hline Gambang & 50 & 25 & $50 \%$ \\
Permatang Badak & 20 & 5 & $25 \%$ \\
Taman Impian & 20 & 5 & $25 \%$ \\
Terminal Sentral & 50 & 10 & $20 \%$ \\
Indera Sempurna & 20 & 5 & $25 \%$ \\
Teluk Cempedak & 20 & 15 & $75 \%$ \\
Indera Mahkota & 30 & 5 & $16 \%$ \\
POLISAS & 30 & 5 & $16 \%$ \\
Taman Gelora & 20 & 5 & $25 \%$ \\
Pekan & 50 & 5 & $10 \%$ \\
Sungai Lembing & 20 & 5 & $25 \%$ \\
Bukit Sagu & 20 & 5 & $25 \%$ \\
Kampong Ubai & 25 & 5 & $20 \%$ \\
TOTAL & 375 & 100 & $27 \%$ \\
\hline
\end{tabular}

\subsection{Location of research}

Kuantan is the capital of Pahang state, Malaysia. It is near the Kuantan River and overlooks the South China Sea. Kuantan is the ninth largest city in Malaysia.

The population of Kuantan is about 607,778 . This population comprises 55\% Malays, 34\% Chinese, $10 \%$ Indian and $1 \%$ other races. There are 13 routes that serve Pahang city and nearest area to cover community moving from urban to rural or vice versa. Fig. 1 indicated the service area of Rapid Kuantan.

Rapid Kuantan is one public bus service in Malaysia other than Rapid KL and Rapid Penang owned by Prasarana Malaysia Berhad Company. It currently has a fleet of 80 Scania K-series buses and operates a total of 18 routes.

\subsection{Validity and reliability test}

This research has twenty-seven questionnaires (five for $\mathrm{X} 1$, five for $\mathrm{X} 2$, four for $\mathrm{X} 3$, four for X4, five for X5, and four for Y). After conducting validity test, any three item of the questionnaire (X1.1, X2.2, and X5.2) are not valid and dropped so we distribute twenty-four (24) item questionnaires to respondents. We also conduct reliability test to know whether each of the independent and dependent variables is reliable or not. Table 2 shows that all of the independent variables have good (2) and excellent (3) reliability with dependent variables.

\section{Results and discussion}

Demographic information is shown in Table 3. Characteristics of respondents in general are: male, adult, have own vehicle, working private or self- 
employed, secondary school and diploma, have income less than RM1,000, Malay, and have traveling frequency 2-5 times a week.

\subsection{Correlation analysis}

Correlation analysis is intended to determine the relationship between five independent variables with one dependent variable. Table 4 shows the correlation between variables.

Based on Table 4, we can describe the correlation between variables either partially or simultaneously, as shown in Fig. 2.

\subsection{Discussion}

Research finding of the relationship between Bus LED Destination with the Passenger Satisfaction is positive significance with $\mathrm{R}$ value is 0.754 , shows a strong relationship.

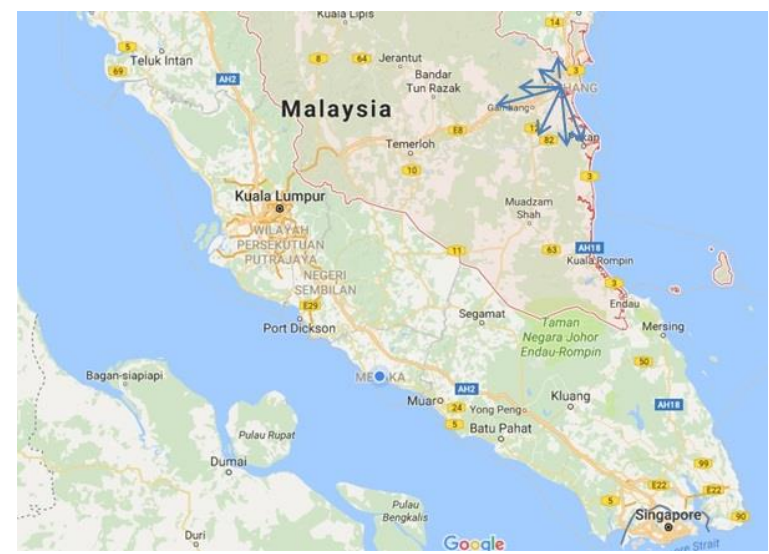

Fig. 1: Service area of rapid Kuantan
Table 2: Reliability test result

\begin{tabular}{ccc}
\hline Independent Variable & Reliability & Result \\
\hline Bus LED Destination & 0.909 & Excellent \\
Bus Next-Stop Sign & 0.916 & Excellent \\
Audio Voice Announcement System & 0.801 & Good \\
Multimedia Passenger Information & 0.888 & Good \\
Bus Station Display System & 0.913 & Excellent \\
\hline
\end{tabular}

Table 3: Demographic information

\begin{tabular}{|c|c|c|c|}
\hline & & Frequency & $\%$ \\
\hline \multirow{4}{*}{ Gender } & Male & 54 & 54 \\
\hline & Female & 46 & 46 \\
\hline & $<20$ & 20 & 20 \\
\hline & $21-30$ & 24 & 24 \\
\hline \multirow[t]{3}{*}{ Age } & $31-40$ & 28 & 28 \\
\hline & $41-50$ & 16 & 16 \\
\hline & $>51$ & 12 & 12 \\
\hline Vehicle & Yes & 69 & 69 \\
\hline \multirow{3}{*}{ Ownership } & No & 31 & 31 \\
\hline & Government & 14 & 14 \\
\hline & Private & 35 & 35 \\
\hline \multirow[t]{4}{*}{ Profession } & Self-employed & 20 & 20 \\
\hline & Student & 23 & 23 \\
\hline & Unemployed & 8 & 8 \\
\hline & Bachelor Degree & 27 & 27 \\
\hline \multirow{5}{*}{$\begin{array}{c}\text { Educational } \\
\text { Level }\end{array}$} & Diploma & 24 & 24 \\
\hline & Secondary School & 38 & 38 \\
\hline & Primary School & 9 & 9 \\
\hline & Others & 2 & 2 \\
\hline & $<$ RM 1,000 & 43 & 43 \\
\hline Income per & RM 1,001-RM2,000 & 26 & 26 \\
\hline \multirow[t]{3}{*}{ Month } & RM 2,001-RM 3,000 & 21 & 21 \\
\hline & $>\mathrm{RM} 3,001$ & 10 & 10 \\
\hline & Malay & 71 & 71 \\
\hline \multirow{4}{*}{ Race } & Chinese & 18 & 18 \\
\hline & Indian & 4 & 4 \\
\hline & Others & 7 & 7 \\
\hline & Daily & 19 & 19 \\
\hline \multirow{4}{*}{$\begin{array}{l}\text { Travelling } \\
\text { Frequency }\end{array}$} & 2-4 times a week & 22 & 22 \\
\hline & 5 times a week & 38 & 38 \\
\hline & Once a week & 5 & 5 \\
\hline & Once a month & 16 & 16 \\
\hline
\end{tabular}

Table 4: Correlation coefficients

\begin{tabular}{cccccc}
\hline \multirow{2}{*}{ Model } & \multicolumn{2}{c}{ Unstandardized Coefficients } & Standardized Coefficients & \multirow{2}{*}{ t } & \multirow{2}{*}{ Sig. } \\
\cline { 2 - 4 } & $\mathrm{B}$ & Std. Error & Beta & & \\
\hline (Constant) & .482 & .214 & 0.754 & .000 \\
Bus LED & .324 & .058 & 0.815 & 2.014 & .001 \\
Bus Next-stop & .448 & .041 & 5.415 & .000 \\
Audio Voice & .354 & .025 & 0.462 & 3.125 & .000 \\
Multimedia Passenger & .425 & .045 & 0.487 & 3.147 & .001 \\
Bus Station Display & .435 & .074 & 0.838 & 4.325 & .000 \\
\hline \multicolumn{7}{c}{ Dependent Variable: Passenger Satisfaction }
\end{tabular}

This finding is in line with Chorus et al. (2007) it's mean if LED board is in good condition and has a very clear display, the passenger satisfaction is higher. The relationship between Bus Next-Stop Sign with the Passenger Satisfaction is positive significance with $\mathrm{R}$ value is 0.815 which shows a strong relationship. Thus the finding is in line with Harmon and Steer (2016). It is essential for the bus operator to help the disabled people to get the information on the bus and at the terminal.

This research found the relationship between Audio Voice Announcement System with the Passenger Satisfaction is positive significance with $\mathrm{R}$ value is 0.462 which shows a moderate relationship. So the finding is in line with Wilson (2014). The audio announcement is triggered more awareness to the bus passenger to get the information regarding the bus service.

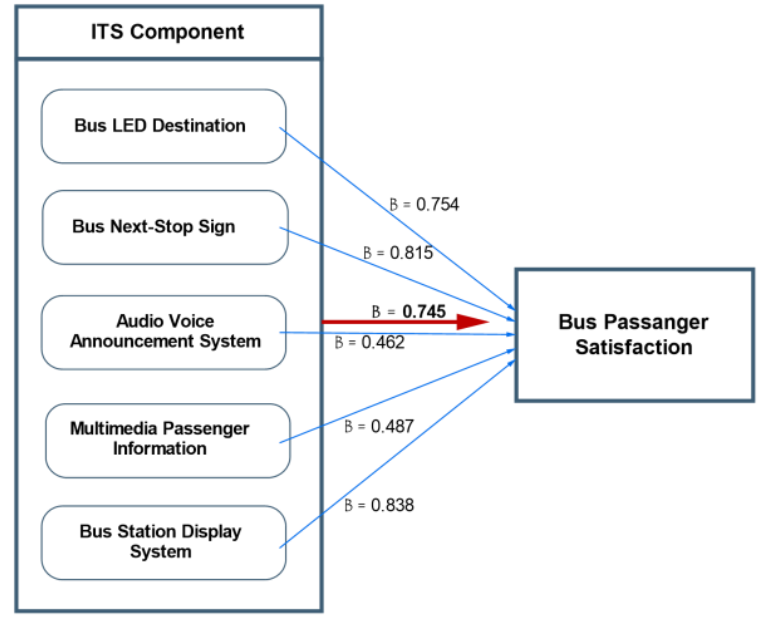

Fig. 2: Correlations of variables 
The relationship between Multimedia Passenger Information with the Passenger Satisfaction is positive significance with $\mathrm{R}$ value is 0.487 which shows a moderate relationship. So the finding is in line with Chung and Shalaby (2007). The multimedia system on the bus such as LCD TV not only brings entertainment but also give information regarding the journey of the bus.

Finding of the research about the relationship between Bus Station Display System with the Passenger Satisfaction is positive significance with $\mathrm{R}$ value is 0.838 which shows a strong relationship. Thus the finding is in line with Diaz et al. (1999). The display system is essential to provide information regarding the schedule and platform for the passenger to make sure the destination. From the correlation analysis of the five components of ITS is the most dominant influence the passenger satisfaction of the bus Rapid Kuantan is BSDS (Bus Station Display System). This is understandable because bus passengers will usually try to get information about the departure and arrival of the bus at the station or bus terminal before the passengers leave on the bus or before the pickup is ready to wait for the family or guests to be picked up.

The relationship between overall ITS with the Bus Passenger Satisfaction simultaneously influence is positive significance because of the $R$ value is 0.745 which shows the strong relationship. Thus the finding shows that the information provided by bus service has satisfied the passenger.

Based on the demographic analysis, the respondent with income below RM 1,000 is the majority of them was an adult that working in private sector or self-employed and have own vehicle, but often use public transport for traveling. The frequency of traveling also influences by the income per month because most of the respondent travels by bus two-five times a week, this is due to relatively cheap bus fare, between RM 1.00 and RM 2.00 .

From the relationship of independent variables with the dependent variable, the most dominant variable that contributes to the passenger satisfaction is Bus Next-Stop Sign because it has the highest $t$ value which is 5.415 when done the multiple regressions (Table 5).

Table 5: Multiple linear regression analysis

\begin{tabular}{ccccc}
\hline \multirow{2}{*}{ Model } & $\mathrm{R}$ & $\mathrm{R}$ & Adjusted $\mathrm{R}$ & Std. Error of the \\
& & Square & Square & Estimate \\
1 & $.725^{\mathrm{a}}$ & .715 & 0.745 & .23415 \\
\hline
\end{tabular}

Thus all the research objectives and the hypothesis are answered within the data analysis is provided.

\section{Conclusion}

The study was made with the intention and hope that these can be one of the contributions in improving the public bus service not only in Kuantan but the whole Malaysia. Therefore, while conducting this research, the researcher hopes that improvement can be made quickly by the authority in order to provide comfort and satisfaction to the passengers who are using the public bus services. In addition, the authorities should take immediate action regarding these matters if they want the citizens to keep using the public bus services without any complaint.

It can be concluded that all the research objectives are achieved with significant correlation of each independent variables to the dependent variable. Overall, the passenger is satisfied with the ITS components that had been implemented by Rapid Kuantan service for providing the information to the passenger. This also shows that the technology is playing an important role in order to help people from both parties. The modern technology used by Rapid Kuantan service can be seen as a benchmark for another public bus service in Malaysia in providing the best service to the passenger.

\section{Recommendation}

Providing passengers with relevant travel information and making their trip safer and more enjoyable is an essential part of the modern transit landscape. In general, recommendations and suggestions were made based on the issues and problems identified. Several recommendations were formulated for the improvement of the passenger information system of the bus service. One of them is to improve the existence ITS components in the bus service. Rapid Kuantan also can share the knowledge and expertise regarding the system with another public bus service in Malaysia to increase the standard of public bus service in the country. The advertisement regarding the system of information in the bus should be published to other potential passengers in order to attract them to travel by public transport. The modern country usually has majority amount of people that travels by public transport as a symbol that it has achieved the level where people can rely on public transport because of its reliability and also comfortability.

Recommendation for further research is to access the whole application of ITS components not only limited to passenger information but also for the bus safety, bus comfortability and also for the operator information. The research can be done in Rapid Kuantan service because it has the latest ITS components in Malaysia. The research regarding the ITS components implementation between our country and the other modern and well-developed country also can be done as a comparative study to analyze what another item that can be added by each country to increase the efficiency of ITS components.

\section{Acknowledgement}

We would like to thank the Universiti Teknikal Malaysia Melaka (UTeM) who has facilitated this research. 


\section{References}

Abu F, Yunus AR, and Jabar J (2015). Modified of UTAUT theory in adoption of technology for Malaysia small medium enterprises (SMEs) in food industry. Australian Journal of Basic and Applied Sciences, 9(4): 104-109.

Adenso-Dıaz B, González MO, and González-Torre P (1999). Online timetable re-scheduling in regional train services. Transportation Research Part B: Methodological, 33(6): $387-$ 398.

Aguilera A (2008). Business travel and mobile workers. Transportation Research Part A: Policy and Practice, 42(8): 1109-1116.

Alexander J and Hill N (2006). The handbook of customer satisfaction and loyalty measurement. Gower Publishing, New York, USA.

Cao X, Mokhtarian PL, and Handy SL (2009). Examining the impacts of residential self-selection on travel behaviour: A focus on empirical findings. Transport Reviews, 29(3): 359395.

Caulfield B and O'Mahony M (2003). Real time passenger information: The benefits and costs. In the Association for European Transport Conference, Strasbourg, France. Available online at: http://www.tara.tcd.ie/

Chorus CG, Arentze TA, Timmermans HJ, Molin EJ, and Van Wee B (2007). Travelers' need for information in traffic and transit: Results from a web survey. Journal of Intelligent Transportation Systems, 11(2): 57-67.

Chowdhury MA and Sadek AW (2003). Fundamentals of intelligent transportation systems planning. Artech House, USA.

Chung EH and Shalaby A (2007). Expected time of arrival model for school bus transit using real-time global positioning system-based automatic vehicle location data. Journal of Intelligent Transportation Systems, 11(4): 157-167.

Diaz AB, Gonzalez OM, and Torre GP (1999). Online timetable rescheduling in regional services. Journal Transportation Research, 33(6): 387-398.

Ferris B, Watkins K, and Borning A (2010). OneBusAway: Results from providing real-time arrival information for public transit. In the SIGCHI Conference on Human Factors in Computing Systems, ACM, Atlanta, Georgia, USA: 1807-1816. https://doi.org/10.1145/1753326.1753597

Handy SL, Cao X, and Mokhtarian PL (2008). The causal influence of neighborhood design on physical activity within the neighborhood: Evidence from Northern California. American Journal of Health Promotion, 22(5): 350-358.

Harmon JA and Steer A (2016). Pivotal year, WRI 2015 Annual Report. World Resources Institute, Washington, D.C., USA. Available online at: www.wri.org/sites/default/files/uploads/ WRI_2015_Annual_Report.pdf
James R and McBride C (2010). Framework for a national intelligent transport systems architecture (No. 397). New Zealand Transport Agency, Wellington, New Zealand.

McDonnell S and Madar J (2011). New York city's plans for bus rapid transit as an investment to generate economic recovery. In the $90^{\text {th }}$ Annual Meeting on Transportation Research Board, No. 11-2772. Available online at: http://docs.trb.org/prp/112772.pdf

Musa HM (2014). Analyzing factors towards adopting ICT within supply network in the UK. The Journal of Technology Management and Technopreneurship (JTMT), 2(1): 19-36.

Schweiger CL (2003). Real-time Bus Arrival Information Systems: A Synthesis of Transit Practice. Transit Cooperative Research Program (TCRP). Transportation Research Board, Washington, D.C., USA. Available online at: www.TRB.org

Shende A, Hathgaonkar S, Patil N, and Jirapure M (2017). Intelligent transport system. International Advanced Research Journal in Science, Engineering and Technology, 4(3): 75-80.

Solomon MR, Marshall GW, and Stuart EM (2008). Real people, real choices: Marketing. Pearson Prentice Hall, New Jersey, USA.

Stradling S, Carreno M, Rye T, and Noble A (2007). Passenger perceptions and the ideal urban bus journey experience. Transport Policy, 14(4): 283-292.

Suh W, Park S, and Lee E (2011). Fault Tolerant intelligent transportation systems with an agent. In the $3^{\text {th }}$ International Conference, Advanced Computer Science and Information Technology, Seoul, Korea: 16-25. Available online at: http://link.springer.com/content/pdf/10.1007/978-3-64224267-0.pdf\#page $=28$

Szyliowicz JS, Zamparini L, Reniers GL, and Rhoades DL (2016). Multimodal transport security, frameworks and policy application and passenger transport. Edward Elgar Publishing, Cheltenham, UK.

Wahjono SI (2010). Bisnis modern. Graha Ilmu Publisher, Yogyakarta, Indonesia.

Wen CH, Lan LW, and Cheng HL (2005). Structural equation modeling to determine passenger loyalty toward intercity bus services. Transit: Planning, Management and Maintenance, Technology, Marketing and Fare Policy, and Capacity and Quality of Service, 1927: 249-255.

Westerheim H, Haugset B, and Natvig M (2007). Developing a unified set of information covering accessibility at public transport terminals. IET Intelligent Transport Systems, 1(2): 75-80.

Wilson JR (2014). Fundamentals of systems ergonomics/human factors. Applied Ergonomics, 45(1): 5-13.

Yao L, Siali F, Darun MRB, and Ismail MF (2014). Service quality and customer satisfaction: rapid Kuantan in Kuantan route, Malaysia. In the SOCIOINT14-International Conference on Social Sciences and Humanities, Istanbul, Turkey: 976-982. Available online at: http://umpir.ump.edu.my/6974/ 